\title{
Jean-Pierre Boulé, Sartre, Self-Formation and
} Masculinities

\section{Emanuele Kanceff}

\section{Q OpenEdition \\ 1 Journals}

\section{Edizione digitale}

URL: https://journals.openedition.org/studifrancesi/26833

DOI: 10.4000/studifrancesi.26833

ISSN: 2421-5856

\section{Editore}

Rosenberg \& Sellier

\section{Edizione cartacea}

Data di pubblicazione: 1 avril 2007

Paginazione: 214

ISSN: 0039-2944

\section{Notizia bibliografica digitale}

Emanuele Kanceff, «Jean-Pierre Boulé, Sartre, Self-Formation and Masculinities», Studi Francesi [Online] 151 (LI | I) | 2007, online dal 30 novembre 2015, consultato il 23 novembre 2021. URL: http:// journals.openedition.org/studifrancesi/26833 ; DOI: https://doi.org/10.4000/studifrancesi.26833

Questo documento è stato generato automaticamente il 23 novembre 2021.

\section{(c) (i) $\odot$}

Studi Francesi è distribuita con Licenza Creative Commons Attribuzione - Non commerciale - Non opere derivate 4.0 Internazionale. 


\title{
Jean-Pierre Boulé, Sartre, Self- Formation and Masculinities
}

\author{
Emanuele Kanceff
}

\section{NOTIZIA}

JEAN-PIERRE BOULÉ, Sartre, Self-Formation and Masculinities, New York-Oxford, Berghahn Books, 2005, pp. 228.

1 Esce in una collana relativamente giovane, "Berghahn Monographs in French Studies", preceduto da un altro studio su Sartre Against Stalinism di Ian H. BIRCHALL, questo Sartre di un noto specialista di studi sartriani, cui si devono tra l'altro un Sartre médiatique (1992) e la cofondazione della Society for Sartrean Studies.

2 Uscito nell'anno del centenario, questo libro giunge a puntino, in un momento di bilanci, per una più lucida ed approfondita indagine di ciò che fu l'uomo Sartre in rapporto alla sua opera, spesso troppo vistosa ed invadente da nasconderne la verità dell'autore. Era dunque tempo di studiarne, come qui si fa, mancanze e compensazioni psicologiche, fin dall'infanzia da fanciullo prodigio, attraverso il delicato periodo che l'autore qualifica di "violence and counter-violence" che prepara la sua maggiore età intellettuale, la quale approda alla "malinconia" esistenziale, scossa e sconvolta, più tardi, dal tema della guerra. E poi, il tempo di Simone de Beauvoir e delle grandi interogazioni sulle relazioni con l'altro.

3 Uno studio fitto e convincente, che contribuisce a gettare nuova luce su un contemporaneo "capitale" e a disegnarne un'immagine psicologica eloquente. 